\title{
Inhalt
}

Vorwort $\ldots \ldots \ldots \ldots \ldots \ldots \ldots \ldots \ldots \ldots \ldots \ldots$ VII

\section{Günter Holtus}

Das "vulgare illustre" als Modell einer italienischen Kunstsprache:

Standard, Substandard und Varietät in Dante Alighieris Traktat

"De vulgari eloquentia" $(1305) \ldots \ldots \ldots \ldots \ldots \ldots \ldots \ldots \ldots$

\section{Klaus Faiß}

Nicht-standardsprachliche und dialektale Erscheinungsformen der englischen Syntax unter Einbeziehung der Sprachgeschichte . . . . . . 14

\section{Klaus Bochmann}

Substandard und rumänische Sprachgeschichte. Ein Forschungsbericht . 41

\section{Johannes Kramer}

Klassische Sprache und Substandard in der Geschichte des Griechischen 55

Lars Johanson

Substandard und Sprachwandel im Türkischen

Norbert Cyffer

Sprachwandel und idiolektale Variation im Kanuri ........... 114

\section{Hartmut Kleineidam / Wolfgang Schlör}

Standard und Non-Standard in der spanischen Grammatikographie . . 131

\section{Beate Henn-Memmesheimer}

Über Standard- und Nonstandardmuster generalisierende Syntaxregeln.

Das Beispiel der Adverbphrasen mit deiktischen Adverbien . . . . . . . 169

Heinz Kröll

Substantivierungs- und Adjektivierungstendenzen von Satzteilen und Sätzen im heutigen Portugiesisch . . . . . . . . . . . . . . . . 229 
